\title{
A Standardized Technique for Establishing Onset and Duration of Symptoms of Alzheimer's Disease
}

\author{
Mary Sano, PhD; D. P. Devanand, MD; Marcus Richards, PhD; Lisa W. Miller; Karen Marder, MD; \\ Karen Bell, MD; George Dooneief, MD; Frederick W. Bylsma, PhD; Ginette Lafleche, PhD; \\ Marilyn Albert, PhD; Marshal Folstein, MD; Yaakov Stern, PhD
}

\begin{abstract}
Objectives: To develop an informant-based semistructured interview to determine the onset and duration of symptoms of Alzheimer's disease, and to use this instrument with informants to characterize a cohort of mildly impaired patients with Alzheimer's disease.
\end{abstract}

Design: In study 1 , interrater and interinformant reliability was examined for the date of onset and the order of appearance for specific symptoms that were elicited by the semistructured onset interview. In study 2 , the instrument was used to characterize disease onset in a cohort of patients with Alzheimer's disease who were participating in a large multicenter study.

Subjects: Informants of patients with Alzheimer's disease.

Results: In study 1, interrater reliability for duration of illness was excellent (intraclass correlation coefficient $=.99, P<.001$ ), and interinformant reliability was good (intraclass correlation coefficient $=.86$, $P<.001$ ). Agreement for the presence of a given symptom was highest for those that were most commonly reported (eg, memory and performance difficulty). In study $2,89 \%$ of the cohort had memory problems, and $63.9 \%$ had performance difficulties as the first or second symptom. Depression and language problems were less commonly reported. Psychosis and behavioral disturbances were rarely reported as the first problem.

Conclusion: This instrument provides a reliable procedure for standardizing the estimation of duration of illness based on retrospective report.

(Arch Neurol. 1995;52:961-966)
From the Departments of Neurology (Drs Sano, Richards, Marder, Bell, Dooneief, and Stern and Ms Miller) and Psychiatry (Drs Devanand and Stern) and the Sergievsky Center (Drs Sano, Richards, and Stern), College of Physicians E Surgeons of Columbia University, the Memory Disorders Center, New York State Psychiatric Institute (Drs Sano, Devanand, Marder, Bell, Dooneief, and Stern and Ms Miller), and the Center for Alzheimer's Disease Research (Drs Sano, Marder, Bell, Dooneief, and Stern), New York, NY; the Departments of Psychiatry and Behavioral Sciences, The Johns Hopkins University, Baltimore, $\mathrm{Md}$ (Drs Bylsma and Folstein); and the Departments of Psychiatry and Neurology, Massachusetts General Hospital, Harvard Medical School, Boston (Drs Lafleche and Albert).

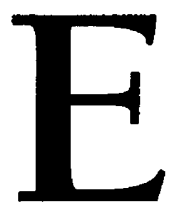

STABLISHING THE date of onset of symptoms of probable Alzheimer's disease (AD) is important for the differential diagnosis and prognosis and for research studies. Epidemiological studies have suggested that patients with an early age at onset have decreased survival. ${ }^{1}$ The rate of progression and the pattern of decline among cognitive skills may be affected by the age at disease onset in patients with AD. ${ }^{2.3}$ Whether familial dementias are associated more with an early than late onset remains unclear. ${ }^{4}$

To determine the age at onset, patient and family member interviews can be used. However, the informant's impression of the onset of illness is often influenced by an event (eg, hospitalization) that was particularly disturbing rather than the earliest sign of difficulty. A standardized, reliable method for assessing onset of illness should have several important characteristics. First, a standardized method for defining the type of symptom is neces- sary, since the label that an informant gives to the symptom may be idiosyncratic or based on an interpretation of a given behavior, rather than an accurate description of the behavior. Second, a list of symptoms must be used for specific queries to ensure completeness. Finally, a standard technique should be used to ascertain the earliest point at which each symptom was present.

This report describes the development of a standardized informant interview for assessing the onset and type of initial symptoms in patients with AD. Interrater and interinformant reliability of the interview was assessed. Finally, the relationship between specific presenting symptoms and indexes of disease severity in a cohort of patients with $\mathrm{AD}$ was examined.

\section{See Subjects and Methods on next page}




\section{SUBJECTS AND METHODS}

\section{STUDY 1}

Study 1 involved the development of a standardized instrument and examination of reliability.

\section{Subjects}

Informants for 36 consecutively encountered patients in a memory disorders clinic were interviewed. Patients met the criteria for a diagnosis of AD according to the National Institute of Neurological Diseases, StrokeAlzheimer's Disease and Related Disorders Association. ${ }^{5}$ Informants were family members or caregivers with frequent contact with the patient. The patients had a mean (SD) age of $70.8(9.2)$ years and a mean (SD) education level of 12.7 (4.0) years. Cognitive impairment was measured with the modified Mini-Mental State Examination (mMMSE). ${ }^{6}$ The mean (SD) mMMSE score for the patients was 28.9 (11.5), which was equivalent to a score of 15 on the mental status examination described by Folstein et al. ${ }^{7}$ A study of interrater reliability was conducted with informants for 23 patients, and a study of interinformant reliability was conducted with informants for 20 patients. Seven patients had informants who participated in both studies

\section{Development of Symptom Categories}

First, seven categories of symptoms were proposed by clinicians who were experienced in the evaluation of dementia. Next, the descriptions of cognitive complaints that were given by informants were compiled from a review of clinical records of 50 patients with AD. Four raters independently reviewed the records of all patients, and they classified the descriptions into seven categories. Most complaints were categorized identically by the raters. Descriptive criteria were developed for the following symptom categories that are listed in Table I: memory, performance, language, disorientation, personality, depressed mood, and behavioral disturbances.

\section{Development of the Semistructured Interview}

The semistructured interview (Table 2) was designed for administration to an informant without the patient present. All interviews began with an open-ended question about the "first problem." Questioning then focused on obtaining a detailed narrative. The "earliest episode" was dated by referencing it to a calendar date. When the informants were unsure, they were instructed to consider a discrete personal event to help establish the date. Additional questions were asked to clarify ambiguity about the date that corresponded to the personal event. Questions were also used to establish a "symptom-free date," defined as the most recent date when the informant was confident that the symptom had never occurred.

Responses to each question were assigned to a symptom category based on the criteria described in Table 1. Symptom categories were rank-ordered chronologically based on the earliest episode. When the informant reported the simultaneous occurrence of two symptoms, the informant was asked to choose which came first, if possible. Symptom categories with the same date for the earliest episode were given equivalent ranks. The rank of 0 signified no symptoms in a given category. The date at disease onset was defined as the earliest episode of the first symptom. "Duration of illness" was defined as the time between this date and the interview date, rounded to the nearest month and year. A manual (available on request) was developed for administration, with regard to scoring and additional probe questions for eliciting symptoms.

\section{Interrater Reliability}

One rater conducted the interview while a second rater simultaneously observed and scored. All interviews for interrater reliability were done in person.

\section{RESLLTS}

\section{STUDY 1 FINDINGS}

The mean duration of illness ranged from 14 to 109 months. In the interrater reliability study, the estimations of duration of the two raters were within 1 month of each other in 19 of the 23 cases. In the remaining four cases, the average difference in duration was 6 months. Interrater reliability for duration of illness was excellent (intraclass correlation coefficient $=.99, P<.001$ ). Agreement for the presence of each commonly reported symptom category was fair to good with $\mathrm{\kappa}$ values between 0.4 and 0.75. (Table 3).

In the interinformant reliability study, agreement (within 1 year) for the duration since the onset of the first symptom was also highly significant (intraclass cor- relation coefficient $=.86, P<.001)$. The percent agreement for the presence of symptoms and the $\kappa$ coefficient for order of appearance of each symptom category are presented in Table 4. When target events are rare or common, the probability of chance agreement is high, resulting in low $\kappa$ values. The rarity of reports of disorientation and depression early in the disease is consistent with the low $\kappa$ values.

\section{STUDY 2 FINDINGS}

\section{Description of the Patients and Informants}

The mean (SD) age of the patients was 72.9 (8.8) years; $41 \%$ were males. The mean (SD) physician estimate of duration was $4.0(2.60)$ years. The mean (SD) education level was 13.1 (3.6) years. The mean (SD) mMMSE 


\section{Interinformant Reliability}

Two informants for each patient were interviewed separately by the same rater. At least one informant was interviewed in person. The other was interviewed in person or by telephone within 2 weeks of the first interview.

\section{Data Analysis}

Intraclass correlation coefficients ${ }^{8}$ were used to examine agreement for duration of illness. Percent agreement was calculated as the number of agreement pairs divided by the total number of pairs. To correct for chance, that is, agreement for the order of symptom appearance, $\kappa$ coefficient values were calculated. It is generally considered that $\mathrm{k}$ coefficient values greater than 0.75 represent excellent agreement; values between 0.75 and 0.40 represent good to fair agreement, and values below 0.40 indicate poor agreement beyond chance. ${ }^{9}$ For interinformant reliability, symptoms within one rank of each other were considered agreements for the $\kappa$ coefficient.

\section{STUDY 2}

Study 2 was a multicenter study with regard to the implications of disease onset and disease severity variables.

\section{Subjects}

Subjects were recruited to participate in a multicenter longitudinal study of predictors of disease course in AD. None of the patients included in this study participated in the reliability study. This cohort consisted of 221 mildly impaired patients ( 99 from Columbia University, New York, NY; 68 from The Johns Hopkins University, Baltimore, Md; and 54 from Massachusetts General Hospital, Boston) who gave informed consent. The details of recruitment procedures and intersite comparisons have been previously described. ${ }^{10}$ The present study includes several patients who were excluded from the longitudinal phase of the multi- center study because their mMMSE score fell below the entry criteria on the official starting date. All patients met the criteria for a diagnosis of AD according to the National Institute of Neurological Diseases, Stroke-Alzheimer's Disease and Related Disorders Association. Only patients and informants who were fluent in English were included.

\section{Procedures}

Training sessions took place at an investigator's meeting before the initiation of the study. Raters were given a manual and a brief introductory lecture about the procedures. Raters then observed and scored an in-person interview that was conducted by the senior author (M.S.), who reviewed the scoring and answered questions. The interview was administered at three different sites by trained research assistants.

The informant's relationship to the patient (spouse, child, sibling, friend, etc), whether he or she lived with the patient, and how much contact he or she had with the patient were recorded. The quality of the information was rated by the interviewer on a five-point Likert scale that ranged from 1 (very good) to 5 (very poor). Clinical data were collected by using the mMMSE, part 1 of the Blessed Dementia Rating Scale (BDRS), ${ }^{11}$ (that rates instrumental activities of daily living, basic self-care activities of daily living, affective and personality changes). An estimate of disease duration and earliest sign was determined independently by a physician based on clinical impression.

\section{Data Analysis}

The percent of cases in which there was an early report (ie, first or second) of the presence or absence of each symptom category was described. Correlational analyses evaluated the relationship between duration of the first symptom and clinical data (BDRS and mMMSE scores, the clinician's estimate of duration). Associations between informant characteristics and duration of illness and the quality of the interview were analyzed with correlational techniques, $\chi^{2}$ test, Student's $t$ test for independent samples, or one-way analysis of variance. score was 37.0 (6.2). The total mean (SD) BDRS score was $8.2(3.5)$, and $66 \%$ of the patients had no difficulty with basic self-care activities of daily living.

More than half of the informants were spouses (56.6\%), $32.1 \%$ were children of the patient, and $11.3 \%$ were friends or others (paid companion, aide, etc). Most $(63.5 \%)$ of the informants lived with the patient, and those who did not had an average of more than three weekly contacts with the patients.

\section{Description of Onset Variables}

The mean (SD) duration, derived by the interview, was 4.3 (3.5) years. As described in Table 5 , the most commonly identified first symptom category was memory, and performance difficulty was the next most common.

The quality of information was judged to be good or very good in $56.4 \%$ of the cases, uncertain in $37.4 \%$ of the cases, and poor or very poor in $6.2 \%$ of the cases. The mean (SD) estimate of duration was 4.0 (3.6) years for cases that were judged to be good or very good, 4.9 (3.4) years for cases that were judged to be uncertain, and $4.5(2.2)$ years for cases that were judged to be poor or very poor. These differences were not significant $(\mathrm{F}=1.49, P=.23)$.

There was a moderate correlation between the physician's and interviewer's estimate of duration $(r=.516$, $P<.001$ ). Both techniques identified memory and performance difficulty as the most common first symptoms (91\% and $65 \%$, respectively).

There was a weak correlation between duration established by the onset interview and mMMSE score $(r=-.115, P=.09)$ and between duration and total BDRS score $(r=.186, P=.005)$. Examination of the subtests of 
Table 1. Description of Symptom Categories

\begin{tabular}{|c|c|}
\hline $\begin{array}{l}\text { Symptom } \\
\text { Category }\end{array}$ & Description \\
\hline Memory & $\begin{array}{l}\text { Difficulty with recalling things (eg, names, all or } \\
\text { important parts of conversations, or lists of } \\
\text { things); forgetting details, appointments, or } \\
\text { messages; losing or misplacing items }\end{array}$ \\
\hline Performance & $\begin{array}{l}\text { Problems with carrying on occupational and } \\
\text { recreational activities; trouble remembering "how } \\
\text { to do" a previously known skill }\end{array}$ \\
\hline Language & $\begin{array}{l}\text { Word-finding problems and misnaming of things; } \\
\text { difficulty with understanding conversation }\end{array}$ \\
\hline Disorientation & $\begin{array}{l}\text { Confusion about the time (including date) and } \\
\text { place }\end{array}$ \\
\hline Personality & $\begin{array}{l}\text { Intensification of a preexisting personality trait; } \\
\text { notable new trait or a marked change, eg, } \\
\text { paranoia (pervasive and unwarranted } \\
\text { suspiciousness and mistrust of people, does not } \\
\text { include other delusions), apathy (socially } \\
\text { withdrawn, loss of interest in usual activities), } \\
\text { egocentricity (selfishness or unawareness of } \\
\text { significant others), dependency (passively } \\
\text { allowing others to assume responsibility for } \\
\text { major areas of life because of inability to } \\
\text { function independently) }\end{array}$ \\
\hline $\begin{array}{l}\text { Depressed } \\
\text { mood }\end{array}$ & $\begin{array}{l}\text { Persistent and severe depressed mood; vegetative } \\
\text { signs are not required }\end{array}$ \\
\hline Behavior & $\begin{array}{l}\text { Physical aggression or verbal abuse; lack of } \\
\text { adequate personal grooming; sexual indiscretion, } \\
\text { including verbal behavior; rigidity or } \\
\text { stubbornness; emotional lability (eg, laughing or } \\
\text { crying inappropriately) }\end{array}$ \\
\hline Psychosis & $\begin{array}{l}\text { Delusion (persistent false beliefs that cannot be } \\
\text { removed by contradictory evidence); } \\
\text { hallucination (a visual, auditory, or olfactory } \\
\text { perception of something that does not exist) }\end{array}$ \\
\hline
\end{tabular}

the BDRS indicated that the correlation was owing to part A of the instrumental activities of daily living $(r=.281$, $P<.001$ ). This may be a result of the limited range in basic self-care activities of daily living scores in these minimally impaired patients.

\section{Relationship Between Onset Characteristics and Informant Characteristics}

The correlation between the amount of informant/ patient contact and the quality of the interview was small and approached significance $(r=.129, P=.06)$, and there was no relationship between the amount of contact and duration $(r=.023, P=.73)$. The quality of information and the estimate of illness duration did not differ between informants who lived with the patient and those who did not.

The quality of the information was good or very good in $58.4 \%$ of spouse informants, $56.3 \%$ of child informants, and $48.0 \%$ of other informants. These differences were not significant $\left(X^{2}=2.5, P=.64\right)$. The mean (SD) duration from spouse informants was 4.3 (3.6) years, the mean (SD) duration from child (of patient) informants was 4.6 (3.3) years, and the mean (SD) duration from other informants was 4.1 (3.5) years. These differences were not significant $(F=0.27$, $P=.76$ )

\section{Table 2. Onset Interview}

\section{Brief instructions}

Ask the questions below and record the verbatim response. If the informant describes physical symptoms rather than cognitive ones, he or she may need to be focused by the interviewer. Questions such as "Have you noticed any problems with thinking or concentrating or memory?" may help the informant understand the type of problem being assessed, and the interview can then continue with the specific questions.

In some cases, the informant will describe an episode that does not appear to meet criteria for the category that is being queried. For the purposes of the interview, the response should be recorded regardless of the match. The proper symptom category is determined by rating the description of each problem or episode in accordance with preset criteria and definitions. This classification is done by the interviewer regardless of the label given by the informant.

For each category, a date must be set when the problem was definitely present. The following questions may be useful to help establish this date: (1) "Do you remember this occurring during any events such as birthdays, anniversaries, or holidays?" (2) "Do you recall what year it was, or what season of the year it was?" (3) "Do you remember where you were or where the patient was when you first noticed the problem?"

The following additional questions can be useful to explain what is meant by a symptom-free time: (1) "When was the last time you think (the patient) was not having this kind of problem?" (2) "When was his or her (name specific category) about the same as yours?" (3) "When was his or her (name specific category) as good as other people of the same age?"

Interview

"I am going to ask you several questions about the very first symptoms or problems you noticed in (patient name). You may be aware of many problems, but this interview will focus on the first or earliest ones." Read the following questions to the informant and record a detailed description of specific events that illustrate the earliest problems.

1. What was the first problem you noticed with ?

(a) When did you first notice this?

(b) When was this not present?

2. Have you noticed memory problems? (if yes to questions 2 through 9 , repeat $[a]$ and $[b]$.)

3. Have you noticed performance changes?

4. Have you noticed language problems?

5 . Have you noticed trouble with knowing the date?

6. Have you noticed personality changes?

7. Have you noticed depression?

8. Have you noticed behavior changes?

9. Have you noticed hallucinations, delusions, or paranoid ideas?

\section{COMMENT}

The results of study 1 indicate that the type and duration of first symptoms can be reliably determined by independent interviewers when a semistructured technique is used. The overall agreement of duration between informants was high. There was agreement between informants for duration of illness and order of appearance of most symptoms. Based on the $\kappa$ value, the agreement for behavioral symptoms was fair, and for depression, it was poor. These symptoms are episodic and may not be witnessed by two informants who see the patient at different times. Another symptom category with poor agreement was disorientation, which some informants attributed to seeing the patient in different contexts. However, there was good agreement for duration, suggesting that 


\begin{tabular}{|lcc|}
\hline \multicolumn{2}{|l|}{ Table 3. Percent Agreement for the Presence } \\
of Commonly Reported Symptoms and $\kappa$ Values* \\
\hline \multicolumn{3}{|c|}{ Interrater Agreement } \\
\cline { 2 - 3 } Symptom Category & $\%$ Agreement & $\kappa$ \\
\hline Memory & 82 & 0.66 \\
Performance & 98 & 0.40 \\
Personality & 90 & 0.75 \\
\hline
\end{tabular}

*For the agreement of order (ie, rank) of each symptom, between independent raters.

\begin{tabular}{|c|c|c|}
\hline \multirow[b]{2}{*}{ Symptom Category } & \multicolumn{2}{|c|}{ Interinformant Agreement } \\
\hline & $\%$ Agreement & $\kappa$ \\
\hline Memory & 100 & 0.68 \\
\hline Performance & 90 & 0.75 \\
\hline Language & 70 & 0.57 \\
\hline Personality & 80 & 0.66 \\
\hline Disorientation & 75 & 0.22 \\
\hline Depression & 75 & 0.23 \\
\hline Behavior & 75 & 0.49 \\
\hline Psychosis & 100 & $\ldots \dagger$ \\
\hline
\end{tabular}

*For the agreement of order (ie, rank) of each symptom, between two informants.

tThe $\kappa$ value could not be calculated since there was $100 \%$ agreement that the symptom was not present.

\begin{tabular}{|c|c|c|c|}
\hline \multirow[b]{2}{*}{ Symptom Category } & \multicolumn{3}{|c|}{$\%$ Reported } \\
\hline & First & Second & Absent \\
\hline Memory problems & 66.2 & 23.0 & 0.5 \\
\hline Performance & 25.9 & 38.0 & 5.9 \\
\hline Personality & 18.0 & 8.3 & 20.0 \\
\hline Depression & 8.8 & 14.6 & 53.2 \\
\hline Disorientation & 8.3 & 20.0 & 18.0 \\
\hline Language & 7.3 & 13.2 & 53.2 \\
\hline Psychosis & 2.9 & 3.9 & 75.0 \\
\hline Behavior & 1.5 & 6.8 & 67.3 \\
\hline
\end{tabular}

the problem was more likely a result of difficulty in ranking the order of symptom appearance. For example, one informant may report that two or more symptoms occurred simultaneously, while another may have noted an interval between the onset of two types of symptoms. Alternatively, two informants may witness the same event, but not recall it similarly, perhaps owing to a differential salience of the event for each informant.

There was a moderate agreement between the onset of illness determined by this interview and the physician's estimate of onset on clinical evaluation. One inherent limitation to both approaches is the reliance on informant recall of events that occurred several years ear- lier. Ideally, prospective longitudinal evaluation of elderly subjects with little or no impairment would be necessary to improve accuracy in the determination of illness onset manifestations.

One method to improve agreement might be to determine if both informants had similar samples of the patient behavior. Furthermore, a reinterview of each informant might also improve the reliability.

In study 2, we used the onset interview to estimate duration of illness in patients who were participating in a multicenter project. Support for the validity of this method was provided by the pattern of symptom onset that was similar to that described by others. ${ }^{12}$ Specifically, memory and performance problems occurred as early and frequently reported symptoms. Behavioral and psychotic features were rare, while depression occurred in about half of the cases.

There was little association between the frequency of contact or the relationship of informant to patient and the quality of the interview. Most informants had contact with the patient at least three times each week, thereby restricting the impact of variable contact on the interview.

The method asked for recall of symptom absence to identify the limits of a behavior. This phenomenon has been labeled "bounded recall" and has been reported to be advantageous in survey and interview techniques. ${ }^{13}$ The semistructured onset interview may be particularly important when more than one condition arises in close conjunction with each other (eg, when dementia occurs close in time to depression, parkinsonism, or signs and symptoms of cerebrovascular disease). In such cases, establishing which condition came first is of considerable value in diagnosis and management.

The method described herein raises the concern that the onset documented may refer to a subclinical period in which an early sign is apparent, but the diagnosis of dementia is questionable. However, the symptoms noted by the informant may result from multiple cognitive deficits, and our onset date may represent a clinical threshold, but disease onset probably precedes this manifestation.

While an individual's complaint of memory may reflect depressive symptoms, ${ }^{14,15}$ the rating of memory changes by a relative/informant is correlated with objective memory scores. ${ }^{15}$ Memory problems that are noted by an informant are predictors of later decline to dementia even when not accompanied by deficits in memory test scores. ${ }^{16,17}$ The Clinical Dementia Rating that is derived by a semistructured interview with an informant and patient evaluates six cognitive categories. ${ }^{18}$ Mild memory complaints that lead to a memory rating of 0.5 in the absence of deficits in any other domain yields an overall Clinical Dementia Rating of 0.5 or "questionable dementia." 19 Follow-up of patients with a Clinical Dementia Rating of 0.5 has shown that $50 \%$ meet criteria for dementia in approximately 1 year, and another $25 \%$ meet criteria in subsequent evaluations. ${ }^{17}$ Informant reports of memory impairment appear to distinguish neuropathologically confirmed cases of very early AD from normal aging. ${ }^{16}$

An important advantage of this technique is that it 
provides a method for establishing baseline markers from which the progression of illness can be measured. The clinical assessment of disease onset is based on the presence of several symptoms. Since this technique uses the onset of a single symptom that is reliably determined, it is more useful in follow-up studies. It provides a method for plotting the natural history of the disease by reliably documenting the onset of each symptom category.

Accepted for publication December 29, 1994.

This study was supported by federal grants AG07370, AG-07232, AG-08702, MH-44176, and RR00645 from the National Institutes of Health, Bethesda, Md, and by The Charles S. Robertson Gift of the Banbury Fund, Cold Spring Harbor, New York, NY. Dr Sano is a former Herbert Irving Assistant Professor in the Department of Neurology, College of Physicians \& Surgeons of Columbia University, New York, NY.

Reprint requests to College of Physicians \& Surgeons of Columbia University, Sergievsky Center, Box 16, 630 W 168th St, New York, NY 10032 (Dr Sano).

\section{REFERENCES}

1. Heyman A, Wilkinson WE, Hurwitz BJ, et al. Early-onset Alzheimer's disease: clinical predictors of institutionalization and death. Neurology. 1987;37:980984.

2. Brandt J, Mellits ED, Rovner B, Gordon B, Selnes OA, Folstein MF. Relationship of age at onset and duration of illness to cognitive functioning in Alzheimer's disease. Neuropsychiatry Neuropsychol Behav Neurol. 1988;2:93-101.

3. Jacobs D, Sano M, Marder K, et al. Age at onset of Alzheimer's disease: relation to pattern of cognitive dysfunction and rate of decline. Neurology. 1994; 44:1215-1220.

4. Breitner J, Silverman JM, Mohs RC, Davis KL. Familial aggregation in Alzhei- mer's disease: comparison of risk among relatives of early- and late-onset cases among male and female relatives in successive generations. Neurology. 1988; 38:207-212.

5. McKhann G, Drachman D, Folstein M, Katzman R, Price D, Stadlan EM. Clinical diagnosis of Alzheimer's disease: NINCDS-ADRDA work group. Neurology. 1984;34:939-944

6. Stern Y, Sano M, Paulson J, Mayeux R. Modified Mini-Mental State Examination: validity and reliability. Neurology. 1987;37(suppl 1):179.

7. Folstein MF, Folstein SE, McHugh PR. 'Mini-Mental State': a practical method for grading the cognitive state of patients for the clinician. J Psychiatr Res. 1975;12:189-198.

8. Shrout PE, Fleiss JL. Intraclass correlations: uses in assessing rater reliability. Psychol Buil. 1979;86:420-428.

9. Fleiss JL. Statistical Methods for Rates and Proportions, 2nd ed. New York, NY: John Wiley \& Sons Inc; 1981:218.

10. Stern $Y$, Folstein $M$, Albert $M$, et al. Multicenter study of predictors of disease course in Alzheimer's disease (the 'predictors study'), I: study design, cohort description and intersite comparisons. Alzheimer Dis Assoc Disord. 1993;7: 3-21.

11. Blessed $G$, Tomlinson $B E$, Roth $M$. The association between quantitative measures of dementia and senile changes in the grey matter of elderly subjects. $B r$ J Psychol. 1968;225:797-811.

12. Rue A, Watson J, Plotkin D. First symptoms of dementia: a study of relatives' reports. Int J Geriatr Psychol. 1993;8:239-245.

13. Bradburn NM, Rips LJ, Shevell SK. Answering autobiographical questions: the impact of memory and inference on surveys. Science. 1987;236:157-161.

14. Bolla K, Lindgren K, Bonnacorsy C, Bleeker M. Memory complaints in older adults: fact or fiction. Arch Neurol. 1991;48:61-64.

15. McGione J, Gupta S, Humphrey D, Oppenheimer S, Mirsen T, Evans D. Screening for early dementia using memory complaints from patients and relatives. Arch Neurol. 1990;47:1189-1193.

16. Morris JC, McKeel DW, Storandt $M$, et al. Very mild Alzheimer's disease: informantbased clinical, psychometric and pathologic distinction from normal aging. $\mathrm{Neu}$ rology. 1991:41:469-478.

17. Morris JC, Fulling K. Early Alzheimer's disease. Arch Neurol. 1988;45:345349.

18. Burke WJ, Miller JP, Rubin EH, et al. The reliability of the Washington University Clinical Dementia Rating. Arch Neurol. 1988;45:31-32.

19. Morris JC. The Clinical Dementia Rating (CDR): current version and scoring rules. Neurology. 1993;43:2412-2413.

\section{ARcints Circulation}

The ARCHIVES is available by request to nonfederal physicians in the United States (50 states and Washington, DC) whose official American Medical Association masterfile record shows a primary specialty of neurology or child neurology in an office- or hospital-based practice as a staff physician, resident in training beyond the first year, or clinical fellow.

If you meet the above qualification criteria and are not currently receiving the ARCHIVES and would like to receive it each month, you must complete a free subscription request card. To receive a request card, please write to Kathryn Osten, American Medical Association, Circulation Processing Department, 515 N State St, Chicago, IL 60610 (FAX 312-464-5831). A subscription request card will be sent to you in response. If you are a resident or fellow, please include verification of your training program and a complete mailing address. 